\title{
Um resgate histórico sobre a importância do Estado no Mercado: o caso do conhecimento nutricional no Brasil
}

\author{
Barbara Michele Amorim ${ }^{1}$
}

\section{Apresentação}

No campo da nutrição, vários atores estão concorrendo por mais legitimidade. 0 discurso corrente correlaciona a temática da alimentação com o tratamento e prevenção de doenças crônicas. Esta vertente é respaldada pelas grandes agências internacionais como, por exemplo, a Organização Mundial da Saúde ${ }^{2}$ - que propõe uma ligação quase que direta entre alimentação saudável e diminuição de doenças. Porém, esta agência não é a única na disputa. Dessa forma, propomos o Estado, a partir de Weber e Durkheim, como um dos principais envolvidos na formulação e manutenção do mercado. Esse artigo propõe um resgate teórico sobre a importância do estado no mercado, em específico, no setor nutricional.

Pensamos as mudanças nos hábitos alimentares como mudanças de comportamento, porém o contrário também é profícuo. Em que cada vez mais os "manuais" emitidos pelas agências nacionais (ANVISA) e internacionais (OMS e OPAS $^{3}$ ) indicam a melhor maneira de se alimentar - o que aos poucos é naturalizada pelas indústrias, pesquisas acadêmicas e grupos sociais. É válido pensar também na influência da mídia nessas transformações, como indica o exemplo de Assunção (2007) que em sua dissertação mostra as práticas alimentares das donas de casa de Tubarão - SC a partir das "dicas" dadas pelos programas culinários televisivos. Principalmente, a rede de reciprocidade que se forma pela troca de receitas e experimentos culinários.

Mestranda em Sociologia Política, PPGSP/UFSC.E-mail: babi.amorim@hotmail.com

Agência fundada em 1948 e subordinada à Organização das Nações Unidas. É especializada em assuntos da saúde (World Health Organization, tradução nossa).

3 Agência fundada em 1902 e subordinada à Organização das Nações Unidas. É especializada em assuntos da saúde no âmbito do continente americano. Serve também de sede da OMS nas Américas (Organização Pan-Americana da Saúde). 
Na maior parte dos documentos normatizadores, tanto os órgãos públicos, como a Agência Nacional de Vigilância Sanitária ${ }^{4}$ (ANVISA), como associações médicas (por exemplo, a Sociedade Brasileira de Cardiologia ${ }^{5}$ ) utilizam o discurso nutricional como fundamento de suas intervenções. A dúvida que emerge é se esse "discurso" é tão homogêneo quanto parece. Como os vários atores envolvidos (industriais, produtores, consumidores, nutricionistas etc.) disputam por legitimidade nesse mercado?

Para Mazon (2010, p.174), os autores da Nova Sociologia Econômica "mostram como interesses e motivações podem ser formulados e reformulados num processo de interatuação Estado e mercado". No caso especifico das regulamentações alimentares, existe uma relação entre o Estado e os mercados da indústria alimentar e da ciência da nutrição.

Essas disputas se intensificam com o advento dos produtos industrializados que por sua vez são "catalisados" pelo aumento do número e tamanho dos supermercados.

Podemos explicar este processo a partir da proposta de que

\begin{abstract}
mudanças no mercado de trabalho criavam uma demanda de consumidores(as) urbanos(as) que, empregados, motorizados e com renda per capita superior, necessitavam de refrigeradores abastecidos mensal ou semanalmente com produtos prontos para o consumo e com prazo de validade alongado (Popkin, 2006). Os supermercados estariam aptos tanto para responder como para criar esta nova demanda (Reardon e Berdegué, 2002). De outro lado, supermercados e indústria agroalimentar alcançaram uma redução secular nos preços dos alimentos processados (Mazon, 2010. p.191).
\end{abstract}

Para verificar a importância e o grau de intervenção dos atores no caso da normatização alimentar no Brasil é necessário retraçar o histórico de cada um. Como proposta deste artigo, aprofundar-nos-emos no papel que o Estado brasileiro ocupa nesse mercado.

Para tal proposta, utilizamos os pressupostos da Nova Sociologia Econômica. Tal tradição sociológica propõe-se a prosseguir e desdobrar o que a

\footnotetext{
$4 \quad$ É a agência reguladora vinculada ao Ministério da Saúde no Brasil. Foi criada em 1999 e é responsável pelo controle sanitário (Agência Nacional de Vigilância Sanitária).

5 A Sociedade Brasileira de Cardiologia (SBC) foi criada em 1943 com o objetivo de investir na educação continuada de seus sócios e à promoção da saúde da população brasileira (Sociedade Brasileira de Cardiologia).
} 
sociologia econômica clássica consolidou. Pensada por teóricos como Weber, Durkheim, Veblen e Simmel, a sociologia econômica deu outras respostas às ações econômicas que não as dadas pela economia institucional. Desde o século XIX a sociologia econômica, elabora teorias críticas aos pressupostos da ciência econômica e expõe seus limites (Raud-Mateddi, 2005).

No presente artigo, buscamos perceber as teorias elaboradas por Bourdieu sobre o campo econômico e a influência de Weber e Durkheim na Nova Sociologia Econômica, principalmente no que diz respeito ao papel do Estado, para verificarmos como estão dispostos os atores nesse mercado. De acordo com RaudMattedi,

Durkheim e Weber iniciaram o estudo sociológico do mercado em termos de construção social, contribuindo assim diretamente para a emergência da nova sociologia econômica na década de 1970. Ambos refletiram sobre o papel das instituições na orientação do comportamento do ator econômico e, portanto, na regulação do mercado, com conclusões frequentemente semelhantes (Raud-Mateddi, 2005, p.128).

Tentamos também, utilizando a ideia do Estado como criador de mercado, verificar como o Estado brasileiro contribuiu para a criação do mercado de conhecimento nutricional. Esse campo é tão vasto e contem tantos atores (cientistas de vários ramos, empresários, governo e demandas sociais etc.) que dificilmente conseguiríamos definir quem nesta rede é o ator predominante. Por esta razão, este artigo tentou perceber o qual espaço ocupa o Estado nessa interação, lembrando que este também é preenchido por atores.

\section{0 campo econômico e o mercado}

De acordo com Bourdieu (2005) e Fligstein (2001) a nova sociologia econômica inclui na analise do campo econômico os aspectos históricos, culturais e políticos, que nas analises da economia são classificados apenas como externalidades. Para a sociologia econômica são as interatuações entre os agentes das trocas que se tornam o foco de pesquisa.

O que Bourdieu propõe, a exemplo de Durkheim, é substituir a ciência econômica por uma economia sociológica, ao argumento de que aquela é baseada em um procedimento metodológico de abstração, que pretende dissociar "uma 
categoria particular de práticas, ou uma dimensão particular de toda prática, da ordem social na qual toda prática esta inserida" (Raud, 2007, p.206).

Para Bourdieu (2005) deve-se reconstruir a gênese tanto das disposições econômicas do campo econômico quanto dos agentes (apud Raud, 2007). "[...] tudo o que a ortodoxia econômica considera como puro dado, a oferta, a demanda, o mercado, é produto de uma construção social, é um tipo de artefato histórico do qual somente a historia pode dar conta" (Bourdieu, 2005, p.17).

As principais críticas de Bourdieu (2005) à teoria econômica tradicional dirigem-se a noção de homo economicus, ao etnocentrismo e à visão a-histórica, que não levam em conta as condições culturais e históricas que se encontram na gênese tanto do campo econômico quanto das disposições dos agentes econômicos. Foi visando questionar a visão antropológica a que a maioria dos economistas, ainda que inconscientemente, filia-se, que Bourdieu (2005) procurou investigar os princípios que regem a formação da esfera econômica, partindo da investigação da própria ação dos agentes até a formação do sistema de preferências e do mercado.

Durkheim e Weber já se opunham à abstração da economia neoclássica propondo uma análise dos atores econômicos concretos, enfocando o conteúdo social das relações mercantis.

Mesmo reconhecendo a possibilidade do ator econômico buscar seu interesse, Durkheim e Weber defendem que esta não é a única razão que explica seu comportamento: a tradição, o direito e a moral também são levados em conta. Além disto, os interesses nada têm de natural, são socialmente definidos (Silva-Mazon, 2010, p. 25).

Para Bourdieu (2005), as relações sociais seriam relações econômicas ampliadas, que podem ser analisadas em termos de interesse, capital, investimento e lucro, que em última instância seriam estendidas a todos os âmbitos da vida social.

O autor lembra que "[...] as trocas nunca são completamente reduzidas a sua dimensão econômica”, ou lembrando Durkheim (1995), “[...] os contratos sempre têm cláusulas não-contratuais" (Bourdieu, 2005, p. 22). A partir de Durkheim, todas as análises sociológicas do mercado versam sobre o fato da 
viabilidade do contrato depender da existência de um fundo institucional composto pela moral, direito e tradição (Raud-Mateddi, 2005).

Se por um lado Bourdieu (2005) considera a lógica econômica como intrínseca a todas as esferas sociais, por outro ele reconhece a independência desta esfera, e a partir desta noção desenvolve o conceito de campo econômico. Com a modernização e tendência e racionalização já identificada por Weber, ele tenta atribuir importância aos interesses, “[...] sobretudo, na sociologia econômica, e relativizar assim o papel assumido pelas relações sociais" (Raud-Mateddi, 2005, p. 205). Essa abordagem torna-se fundamental para explicar a origem dos conflitos, que ocorrem por conta de uma disputa de interesses (Raud-Mateddi, 2005).

Rompendo com a tradição clássica da chamada "mão invisível”, o sociólogo francês define o mercado como uma construção social, espaço histórico e culturalmente construído através das noções de demanda e oferta, estas igualmente construídas no mesmo processo (Raud-Mateddi, 2005). Nesta construção, o Estado tem papel fundamental, um duplo papel como produtor das disposições individuais (demanda) e através da definição dos privilégios e das estruturas de acesso ao mercado (Bourdieu, 2005).

Bourdieu (2005) dá seqüência à análise weberiana do mercado, na qual "[...] toda troca racionalmente orientada é a conclusão mediante um compromisso de uma prévia luta de interesses aberta ou latente" (Weber, 1991, p. 43). 0 autor pensa o campo econômico como um "campo de lutas”, “[...] um campo de ação socialmente construído onde se afrontam agentes dotados de recursos diferentes" (Bourdieu, 2005, p. 33). Os diferentes atores disputariam a apropriação de seu capital específico mediante estratégias que são determinadas pela sua posição na estrutura social e a quantidade de capital ou recurso disponível para tanto. Para Bourdieu (2005), o capital classifica-se em: financeiro, comercial, simbólico e tecnológico, que no campo estão distribuídos de diferentes formas. Assim, as estratégias de luta não seriam definidas unicamente pelo livre interesse dos agentes, nem tampouco pelo cálculo estritamente utilitarista, mas, estariam condicionadas à pressão estrutural do campo, bem como à posição relacional do agente em relação aos demais parceiros de troca (Bourdieu, 2005). 
Com isso chegamos à dimensão política inerente a toda relação econômica, em que Bourdieu (2005) rompe mais uma vez com o pensamento corrente ao afirmar que os agentes econômicos não se encontram em igualdade de posições, mas são dotados de diferentes quantidades e formas de poder, exercendo ou sofrendo dominação.

Lembramos que o campo é um subsistema social, ou um espaço estruturado de posições, onde os diferentes agentes que ocupam as diversas posições lutam, tendo em vista a apropriação do capital específico ao campo e/ou a redefinição desse capital (Raud-Mateddi, 2005, p.210).

Partimos deste referencial teórico para entender as relações assimétricas no campo de distribuição alimentar. Neste campo, emergem atores poderosos a partir da OMS, por exemplo, no setor alimentar, surge o Codex Alimentarius ${ }^{6}$. No Brasil, a ANVISA norteia-se por esse órgão, porém gera controvérsias quanto ao conteúdo de suas resoluções. Mesmo desta forma, como nos lembra Silva-Mazon (2005) ao citar Fligstein, os relacionamentos entre as empresas com seus fornecedores; seus trabalhadores; e seus competidores em busca de vantagens sobre novas tecnologias dependem da construção de instituições estáveis tais como governo e leis.

Tanto governos, como firmas e trabalhadores têm resolvido seus problemas coletivos produzindo regras para ajudar a estabilizar suas interações. Estas soluções têm variado historicamente e através das sociedades e dependem em grande parte do poder relativo de diferentes grupos para produzir o Estado moderno (Silva-Mazon, 2005, p. 47).

Essa peculiaridade histórica/cultural da qual nos fala Fligstein (2001) e Mazon (2005) é verificável no Brasil. Por conta das "fragilidades" encontradas nas normativas brasileiras, os outros atores, como a Associação Brasileira de

6 O Codex Alimentarius é um Programa Conjunto da Organização das Nações Unidas para a Agricultura e a Alimentação - FAO e da Organização Mundial da Saúde - OMS. Trata-se de um fórum internacional de normalização sobre alimentos, criado em 1962, e suas normas têm como finalidade proteger a saúde da população, assegurando práticas eqüitativas no comércio regional e internacional de alimentos, criando mecanismos internacionais dirigidos à remoção de barreiras tarifárias, fomentando e coordenando todos os trabalhos que se realizam em normalização (Comitê Codex Alimentarius do Brasil). 
Supermercados ${ }^{7}$, Associação Brasileira das Indústrias da Alimentação ${ }^{8}$ e Associação Brasileira de Nutrição ${ }^{9}$, conseguem manipular ainda mais o mercado para conseguirem os resultados esperados.

Raud (2007, p.226) afirma ainda que assim como “[...] em Weber, encontramos em Bourdieu a convicção de que é a sociedade que legitima os fins e os meios dos agentes econômicos". Isto equivale dizer que a esfera econômica é como as demais esferas sociais um universo de crenças em que as dimensões simbólicas são de fundamental importância no engrendamento das relações, que são baseadas em um sistema de valores que orienta a ação dos indivíduos.

Bourdieu (1996) observa que os sujeitos são de fato agentes que atuam e que sabem, dotados de um senso prático, de um sistema adquirido de preferências, de princípios de visão e de divisão, de estruturas cognitivas duradouras (que são incorporação de estruturas objetivas) e de esquemas de ação que orientam a percepção da situação e a resposta adequada. O habitus é essa espécie de senso prático do que se deve fazer em determinada situação (Bourdieu, 1996:42). Ao falar do campo econômico, Bourdieu (2005) observa que estas disposições "são adquiridas em e por meio de uma experiência precoce e prolongada das necessidades do campo" (id, ibid:19). (Silva-Mazon, 2010, p.39).

Constata-se, assim, que embora o campo econômico seja politicamente constituído por dominantes e dominados, estas posições não são estáticas, podendo sofrer revezamentos no interior do campo. Ele observa que as empresas dominantes têm margem maior de liberdade e que não é possível ignorar as posições que os diversos atores têm no campo, pois as pressões não vão ser as mesmas dependendo desta posição (Silva-Mazon, 2010, p. 39).

A partir de indicativos, podemos perceber mais uma vez como o mercado não é estático e também não assume uma única posição frente as decisões. Todos

\footnotetext{
7 ABRAS - A Associação Brasileira de Supermercados foi criada em 1968 para promover e prover de forma mais acelerada e qualificada o desenvolvimento do setor, com pesquisas e estudos que permitem conhecer cada vez mais o segmento e contribuir para a educação da mão-de-obra supermercadista, capacitando-a e qualificando-a (Associação Brasileira de Supermercados).

$8 \quad$ ABIA - A Associação Brasileira das Indústrias da Alimentação - foi criada em 1963 com o objetivo de congregar as empresas que se dediquem à indústria da alimentação e funcionar como interlocutor, junto ao Poder Público, na qualidade de Órgão Técnico e Consultivo (Associação Brasileira das Indústrias da Alimentação).

9 ASBRAN - a Associação Brasileira de Nutrição foi criada em 1949, e antes se chamava Associação Brasileira de Nutricionistas (ABN) e Federação Brasileira das Associações de Nutricionistas (FEBRAN) (Associação Brasileira de Nutrição).
} 
os atores estão sempre disputando maior legitimidade frente ao Estado, ao consumidor, aos trabalhadores e também aos concorrentes. Voltando a Weber, os atores sempre se orientam "[...] pela ação potencial de uma pluralidade indeterminada de outros interessados também concorrentes, reais ou imaginados" (Raud-Mateddi, 2005, p.130).

Mas precisamos voltar e traçar um histórico da legitimidade requerida pela nutrição no Brasil. Com isso, voltamos à década de 1930. Em seu livro "Mal de fome e não de raça", Lima (2000) propõe um estudo da história da nutrição no Brasil e as transformações que ocorreram de 1934 a 1946.

Uma das vertentes teóricas sobre o problema da fome é Josué de Castro. $\mathrm{Na}$ época, havia uma concordância entre a postura do Estado brasileiro e o que era defendido por Castro. 0 mal da fome, para o autor, era uma falha do Estado brasileiro.

O autor era o defensor de bases biológicas e sociais (com
indicadores de nutrição) como fonte de cálculos para as
potencialidades nacionais: a baixa produtividade do faminto
geraria baixa produtividade para o país. No lugar do paradigma
racial-climático proposto por Euclides da Cunha e Oliveira Viana
para explicar os defeitos do Brasil ele propõe pensar a má
alimentação: 'a baixa vitalidade do brasileiro seria um mal de
fome e não de raça', os salários miseráveis seriam insuficientes
para o consumo alimentar (Bizzo apud Silva-Mazon, 2010, p. 182).

Várias foram as ações de Castro no Brasil. Ele criou e dirigiu vários órgãos nacionais no período da modernização do Estado: em 1939, Serviço Técnico de Alimentação Nacional, o Serviço de Alimentação da Previdência Social, Instituto de Tecnologia Alimentar, Instituto de Nutrição da Universidade do Brasil (INUB) e a Comissão Nacional de Alimentação (CNA), entre 1945 a 1954 (Bizzo apud SilvaMazon, 2010). “Castro também atuou como vice-presidente da Comissão Nacional de Política Agrícola da era Vargas e criou um periódico 'Arquivos Brasileiros de Nutrição" (Silva-Mazon, 2010, p. 183).

Foi a partir de 1944 que surgiu a primeira faculdade de nutrição. Seu objetivo principal foi produzir uma ração alimentar ideal para o brasileiro e "ensiná-lo" a se alimentar. Utilizava o método fisiológico e geográfico para mapear os regionalismos e identificar em qualquer lugar a subnutrição, mesmo entre os 
mais abastados, pois para os cientistas, até estes não sabiam se alimentar (Lima, 2000)

Pode-se perceber que desde seu inicio no Brasil, o Estado, através do campo da nutrição, tomou para si a legitimidade de impor uma alimentação racional e "melhor" para a população. Hoje não é muito diferente, a hipótese de que a nutrição é legitimada pelo Estado e também pelos meios de comunicação é enfática. Porém, mesmo através dos guias alimentares em que o governo tenta homogeneizar a alimentação básica nacional e introduzir políticas públicas há disputas por legitimidade e poder diante da tomada de decisões.

Silva-Mazon (2005, p.48) lembra-nos que na década de 1990

[...] Estado brasileiro além de retirar os subsídios da agricultura também cria o ambiente favorável à entrada dos grandes grupos supermercadistas no país que concentram grande parte da comercialização de alimentos; fenômeno observado não só no Brasil, mas também ao nível mundial.

Este processo de disputa por legitimidade constitui a dinâmica interna do mercado. Em suas relações externas, a de maior importância estabelece-se com o Estado, que por deter poder de regulamentação, tem enorme influência, podendo situar os agentes em melhor posição de acesso a informações, recursos ou privilégios. Assim é que muitas vezes as tensões no interior do campo constroemse em torno da competição pelo poder e ascendência sobre o Estado (Bourdieu, 2005).

\section{0 papel do Estado no mercado}

Os Estados ao se construírem, constroem os diferentes mercados (Fligstein, 2001; Bourdieu, 2005). A partir do processo de interatuação entre mercado e Estado, novos arranjos institucionais são criados. "Instituições referem-se a regras compartilhadas, que podem ser leis ou entendimentos coletivos, mantidos pelo costume, por um acordo explícito ou implícito" (Fligstein,2001, p. 29).

0 Estado, sendo uma dessas instituições, contribui para a criação do mercado. Tanto pela transformação nos direitos de propriedade, como estabilizando as iterações dos agentes envolvidos (Silva-Mazon, 2010 e 2005). 
Retomando a sociologia econômica de Durkheim e Weber, Raud-Mattedi (2005, p.130) propõe que "[...] as instituições organizam as relações sociais e as atividades econômicas". Isto acontece porque as instituições regulamentam os conflitos de interesse, e também porque auxiliam na formulação dos interesses individuais (Silva-Mazon, 2010).

O Estado não somente é o encarregado de garantir a confiança e a ordem, e de regular as empresas e os mercados, mas "[...] ele contribui, às vezes de maneira extremamente decisiva, para a construção da demanda e da oferta" (Bourdieu, 2005, p. 41).

Mesmo quando o país investe nas instituições de ensino superior e pesquisas científicas, está auxiliando a criar um campo de conhecimento da nutrição. Depois esse mesmo ator irá a outras instituições estatais para garantir continuidade de seu habitus e a legitimidade de seu conhecimento.

0 Estado é um dos atores preferenciais na construção e
manutenção dos arranjos institucionais; criando as leis e
regulamentações relativas à política fiscal, ao capital financeiro, à
concorrência, às relações salariais, às patentes e aos direitos de
propriedade; promove compras públicas; financia a pesquisa e a
construção de infraestruturas; participação no capital de
empresas (água, eletricidade); garante juridicamente a aplicação
dos contratos e tem ainda as funções de assistência social (como
creches para que as mulheres trabalhem) e redistribuição (Silva-
Mazon, 2010, p. 48).

A ANVISA, como representante do Estado nos assuntos de sanitários e de alimentação e desde 1999 como instrumento privilegiado, regula todo o processo de produção, transporte e vendas de alimentos do Brasil, principalmente os processados. Por essa razão, ela é uma instituição que reúne os mais diversos atores com os mais diversos interesses.

Para Bourdieu (2005), o campo econômico é formado por atores que ocupam lugares diferentes por terem diferentes tipos de capital. Mesmo que seja o Estado a estabelecer as leis, há também uma pressão por parte dos outros agentes, principalmente os dominantes. Weber já afirmava isso quando propunha que há sempre uma intersecção entre os campos político, econômico e jurídico (SilvaMazon, 2010; Raud-Mateddi, 2005). 
Neste sentido, as mudanças ocorridas no interior do campo são levadas a efeito principalmente pelas empresas dominantes, especialmente em suas interações com o Estado. Este último tem vital importância na construção social do mercado e pode influenciar decisivamente as relações de força no interior do campo econômico, pois é em grande medida responsável pela construção da demanda e oferta, encontrando-se na "gênese social dos sistemas de preferência" (Bourdieu, 2005; Raud-Mateddi, 2005).

A ANVISA é a responsável pela publicação de informes técnicos que regularizam a produção, investimento em tecnologias, comercialização e embalagem dos alimentos. Por ter tantos grupos interagindo (técnicos, burocratas, industriais, opinião pública etc.) que por vezes ela apresenta impasses, fragilidades e mesmo controvérsias em suas ações.

Mas a regulação dos alimentos e também, de forma implícita, do saber nutricional pelo Estado brasileiro não iniciou em 1999, pois em 1969 foi publicado o Decreto-Lei no 986, em que ficaram estabelecidos os conceitos de alimento e suas modificações. 0 artigo $2^{\circ}$ traz as seguintes definições:

- $\quad$ Alimento: toda substância ou mistura de substâncias, no estado sólido, líquido, pastoso ou qualquer outra forma adequada, destinadas a fornecer ao organismo humano os elementos normais à sua formação, manutenção e desenvolvimento;

- Matéria-prima alimentar: toda substância de origem vegetal ou animal, em estado bruto, que para ser utilizada como alimento precisa sofrer tratamento e/ou transformação de natureza física, química ou biológica;

- Alimento in natura: todo alimento de origem vegetal ou animal, para cujo consumo imediato se exija, apenas, a remoção da parte não comestível e os tratamentos indicados para a sua perfeita higienização e conservação;

- Alimento enriquecido: todo alimento que tenha sido adicionado de substância nutriente com a finalidade de reforçar o seu valor nutritivo;

- $\quad$ Alimento dietético: todo alimento elaborado para regimes alimentares especiais destinado a ser ingerido por pessoas sãs;

- $\quad$ Alimento de fantasia ou artificial: todo alimento preparado com o objetivo de imitar alimento natural e em cuja composição entre, preponderantemente, substância não encontrada no alimento a ser imitado; (BRASIL, 1969). 
Após alguns anos, resoluções e portarias foram criadas para adequarem a Lei 986/69 às novas inovações no campo da alimentação.

Todas essas classificações moldam não somente a produção, mas também a criação de alimentos por parte das indústrias. Podemos pensar que mais que isso, pois com essas publicações norteiam também toda a opinião pública com relação aos alimentos.

Para compreendermos melhor os fundamentos teóricos de Bourdieu, voltamos aos clássicos Durkheim e Weber para perceber qual a importância que cada um deles dá ao Estado.

Para Durkheim, o Direito moderno assegura uma confiança no mercado, pois pune os atos desonestos (Raud, 2007). "A sanção dos contratos consiste, então, essencialmente, não em vingar a autoridade pública da desobediência, como no caso do devedor recalcitrante, mas em assegurar, às duas partes, a plena e direta realização dos direitos adquiridos" (Bourdieu Apud Raud, 2007, p. 135).

Para Durkheim, o Estado é um mais órgão deliberativo e executivo, pois ele é o encarregado de elaborar as representações que são validas na sociedade (Raud, 2007). 0 autor formula uma explicação que permite ultrapassar a teoria econômica que trabalha as trocas apenas influenciadas pelos interesses individuais.

[...] o interesse aproxima os homens apenas por alguns instantes. Onde o interesse reina sozinho, nada vem refrear os egoísmos em presença, cada eu se encontra em face do outro em pé de guerra e uma trégua nesse eterno antagonismo não poderia ser de longa duração. De fato, o interesse é o que há de menos constante no mundo (Durkheim, 2004, p.189).

Para permitir que as relações econômicas sejam possíveis e que perdurem para além do momento da troca, Durkheim propõe o Estado como regulador fundamentalmente moral. E quanto mais se tenta afastar o Estado das trocas mercantis, mais dependentes delas estão, pois o Estado sugere um sentimento de solidariedade comum (Raud, 2007).

Ao contrário do que diz a teoria econômica sobre o Estado - que com o advento da modernidade ele perderia suas funções primordiais na esfera econômica -, Durkheim diz que ele pode ter se afastado de suas funções 
tradicionais - como a guerra -, mas em contrapartida assumiu novas responsabilidades em áreas como a saúde, educação e comunicação, por exemplo (Raud, 2007). "Nesse sentido, o crescimento do individualismo não implica a diminuição do papel do Estado; pelo contrário, é justamente o Estado que legitima e garante o individualismo, que afirma e faz respeitar os direitos do indivíduo" (Raud, 2007, p. 138).

Como exposto acima, foi a partir das leis que o Estado brasileiro pôde definir e delimitar a ação dos outros agentes, como por exemplo, as indústrias e os produtores rurais. É a confiança dos consumidores na legislação e fiscalização do Estado que auxilia na escolha dos alimentos. Caso contrário, todo produtor, indústria, supermercadista e outros teriam que provar sua qualidade e buscar a confiança do consumidor a cada troca mercantil. Por outro lado, os consumidores teriam que buscar muito mais informações e vínculos parta poder garantir a qualidade do que estaria consumindo.

A regulação do mercado pode ter quatro tipos de causa: tradicional, convencional, jurídica ou voluntária (Weber, 1991). Essa classificação permitiu a Raud (2007) abordar os temas das regras jurídicas, da tradição e das regras morais, e acrescentar uma análise do papel do Estado para além do Direito.

Para Weber, o papel do Estado é o de assegurar as regras do jogo, em particular um sistema monetário racional, não fazendo flutuar a moeda em função de interesses políticos. Em segundo lugar, o Estado através da burocracia participa da difusão de um ethos que entra em relação de reforço com o ethos capitalista, ou seja, a ênfase na impessoalidade e racionalidade (Silva-Mazon, 2010, p. $45)$.

Esta característica respalda o fato de a dominação legal ser a mais adaptada à economia de mercado, dentre as três formas de dominação. Isso devido à lógica de funcionamento da burocracia, com suas regras estáveis e definidas, e a ausência de arbitrariedade (Raud, 2007).

Para Weber, o Estado contribui para a manutenção de uma determinada mentalidade econômica. Porém, não é a política econômica que pode influenciar o comportamento do ator econômico, mesmo que direta e voluntariamente (Raud, 2007). 
Para este autor a norma não explica a ação social, mas ela é sim uma apropriação que o ator pode fazer da instituição. Este respeito a uma regra social consiste numa ação social que pode ser orientada a fins, a valor, pelo afeto ou pela tradição (Silva-Mazon, 2010).

Podemos voltar ao assunto das fragilidades na legislação brasileira relacionada aos alimentos. A Lei formulada pela ANVISA delimita as ações, mas não as fecha duramente. Assim, cada sujeito desse campo pode interpretá-la e fazer uso dessa interpretação. Isso não caracteriza uma atitude errada da ANVISA, mas permite que os diferentes atores, com suas diferentes intenções, tenham possibilidade de manobrar e interagir no campo.

Podemos agora perceber algumas características similares aos autores e que permitem verificar porque estes clássicos são retomados pela Nova Sociologia Econômica.

\begin{abstract}
Ambos os autores insistem, portanto, na importância do Direito para manter a confiança no mercado, ao assegurar o respeito aos contratos e à propriedade privada, duas instituições fundamentais. Cada um traz ainda uma contribuição adicional e diferenciada: Durkheim lembra que o Direito permite economizar o tempo social; Weber mostra o papel do Direito na implementação de um ambiente estável e previsível (Raud, 2007, p. 137).
\end{abstract}

Autores da Nova Sociologia Econômica enfatizam a natureza interativa das relações entre as ações individuais e as instituições. 0 indivíduo usa os modelos institucionais disponíveis ao mesmo tempo em que os confecciona (Bourdieu, 2005; Fligstein, 2001; Silva-Mazon, 2010).

$\mathrm{Na}$ sociologia econômica weberiana a relação mercantil é uma relação social na medida em que os atores devem levar em conta não somente o comportamento dos outros atores econômicos, mas, também o contexto sócio-político. São os interesses próprios que orientam a atividade econômica e também a ação futura e previsível de terceiros (Silva-Mazon, 2010, p. 23).

Uma das principais diferenças entre o pensamento da escola francesa, aqui representada pelas obras de Durkheim e Bourdieu e a escola alemã - representada por Weber -, é que a primeira pretende uma teoria que substitua a teoria 
econômica neoclássica e a segunda pretende auxiliar a teoria econômica naquilo que a sociologia pode oferecer: as teorias das ações sociais e dos agentes.

\section{Conclusão}

Com este artigo percebemos quão complexa e inexplorada é a área da Nova Sociologia Econômica. Como proposta de análise das ações sociais, permite que uma profícua explicação, principalmente por levar em consideração que o mercado é um espaço de interações sociais.

Outra característica importante é a possibilidade de ver o papel do Estado como constituidor de mercado. Não somente porque ele regula e permite uma confiança nas trocas mercantis, mas também porque, a partir de leis e ações, pode criar demanda e permitir a criação de ofertas.

No caso do mercado do conhecimento nutricional no Brasil, o Estado faz-se presente desde o incentivo às pesquisas acadêmicas e de empresas privadas, passando pela legislação da fabricação, embalagem, logística e comercio de produtos alimentícios, até a permissão da entrada de novos atores no mercado, como os investimentos estrangeiros e a abertura de supermercados.

É necessário mais estudos sobre este campo, principalmente para podermos perceber como estes outros atores, além do Estado, articulam capitais para poder manipular o campo. Foi possível verificar, de forma exploratória e panorâmica algumas ações do Estado brasileiro na criação e manutenção desse mercado, mas investigações mais aprofundadas devem ser realizadas para melhor entender o campo e a agencia dos atores.

\section{Referências}

AGÊNCIA NACIONAL DE VIGILÂNCIA SANITÁRIA. Disponível em: <http://portal.anvisa.gov.br> Acesso em: 31/10/2011.

ASSOCIAÇÃO BRASILEIRA DAS INDÚSTRIAS DA ALIMENTAÇÃO. Disponível em:< http://www.abia.org.br/default.asp > Acesso em: 31/10/2011.

ASSOCIAÇÃO BRASILEIRA DE NUTRIÇÃO. Disponível em:

<http://www.asbran.org.br/> Acesso em: 31/10/2011. 
ASSOCIAÇÃO BRASILEIRA DE NUTRIÇÃO. Os cursos de nutrição no Brasil. In Historico do nutricionista no Brasil: 1939 a 1989 : coletânea de depoimentos e documentos. São Paulo: Atheneu, 1991. p. 7-136

ASSOCIAÇÃO BRASILEIRA DE SUPERMERCADOS. Disponível em: $<$ http://www.abrasnet.com.br/> Acesso em: 31/10/2011.

ASSUNÇÃO, V. K. Nem toda receita é "Mais você": estudo etnográfico sobre consumo e recepção de programas televisivos de culinária em camadas médias e populares. Florianópolis, 2007. 126 f. Dissertação (Mestrado) - Curso de Antropologia Social, Departamento de Programa de Pós-graduação em Antropologia Social, Universidade Federal de Santa Catarina, Florianópolis, 2007.

BOURDIEU, P. O campo econômico. Revista Política e Sociedade, vol. 6, Florianópolis: Cidade Futura. 2005. p. 15-57.

BRASIL. Decreto-Lei no 986, de 12 de outubro de 1969. Institui normas básicas sobre alimentos. Diário Oficial da União (D.O.U.), Brasília, 21 de outubro de 1969. Diário Oficial da República Federativa do Brasil. Brasília, 1969.

COMITÊ CODEX ALIMENTARIUS DO BRASIL. Disponível em $<$ http://www.inmetro.gov.br/qualidade/comites/ccab.asp> Acesso em: $31 / 10 / 2011$.

DURKHEIM, E. Da divisão do Trabalho Social, trad. E. Brandão, 2a. ed., São Paulo:Martins Fontes. 2004.

FLIGSTEIN, N. Mercado como política: uma abordagem políticocultural das instituições de mercado, Revista Contemporaneidade e Educação, ano 6 (9). 2001. p. 26-55.

GRISOTTI, M. et al. Os alimentos funcionais em supermercados no Brasil e na Holanda: análise sociológica da construção social das alegações de saúde e o seu papel nas políticas de saúde pública e no perfil das escolhas dos consumidores. Relatório de pesquisa - processo n. 484982/2007-9 - 2010. Edital MCT/CNPq 
LIMA, E.S. Mal de fome e não de raça: genese, constituição e ação politica da educação alimentar, Brasil 1934-1946. Rio De Janeiro: FIOCRUZ 2000. 282p

ORGANIZAÇÃO PAN-AMERICANA DA SAÚDE . Disponível em:

<http://new.paho.org/bra/> Acesso em: 31/10/2011.

RAUD-MATTEDI, C. A construção social do mercado em Durkheim e Weber. Análise do papel das instituições na sociologia econômica clássica. Revista Brasileira de Ciências Sociais - RBCS, vol. 20 (57). 2005. p. 127-142.

RAUD, C. Bourdieu e a nova sociologia econômica. Tempo Social. Revista de Sociologia da USP, vol. 19(2), 2007. p. 203 -232.

SILVA-MAZON, M. Abastecimento alimentar no Brasil e as reformas liberalizantes: estado e mercado em questão. 2010. 232 p. Tese (Doutorado) Programa de Pós-Graduação em Sociologia Política, Universidade Federal de Santa Catarina, 2010.

. A construção social do mercado olerícola. Estudo de caso em UrubiciSC. Dissertação (mestrado). Programa de Pós Graduação em Sociologia Política UFSC - Florianópolis, 2005.

SOCIEDADE BRASILEIRA DE CARDIOLOGIA. Disponível em: < $\underline{\text { http://www.cardiol.br/> }}$ Acesso em: 31/10/2011.

WANDERLEY, F. Avanços e desafios da Nova Sociologia Econômica. Notas sobre os estudos sociológicos de mercado. Sociedade e Estado. NSE. Vol. 17 (1), Brasilia: UNB. 2002. p. 15-38.

WEBER, M. Economia e Sociedade Trad. R. Barbosa e K. E. Barbosa, São Paulo: UNB/Imprensa Oficial, vol. I, 4a. edição. 2004.

WORLD HEALTH ORGANIZATION. Disponível em: <http://www.who.int/en/> Acesso em: 31/10/2011. 


\title{
Resumo
}

0 mercado do conhecimento nutricional no Brasil tem como um dos principais atores o Estado. Esse texto propõe um resgate teórico que discute essa atuação, o que nos remete às teorias da Nova Sociologia Econômica. A partir da noção de campo econômico em Bourdieu e do papel do Estado no mercado em Weber e Durkheim, pudemos perceber a dinâmica do mercado de conhecimento nutricional no Brasil. Foi utilizando a ideia do Estado como criador de mercado que verificamos como o Estado brasileiro contribuiu para a criação desse mercado e como estão dispostos os outros atores.

Palavras-chave: mercado; nutrição; Estado.

\begin{abstract}
The market of nutrition based on knowledge has as one of its main actors the State itself. This paper proposes a theoretical work that discusses this acting, which brings us to the theories of the New Economic Sociology. Form the category of economic field in Bourdieu e de role of the State in Weber and Durkheim, we could perceive the dynamics of the nutritional knowledge market itself in Brazil. It was utilized the idea of the State as a market creator form which we verified how the Brazilian state contributed to the fulfilling of this on purpose.
\end{abstract}

Key-words: market; nutrition; state 